\title{
La educación inicial como dispositivo de gobierno de la infancia en Colombia
}

\section{Early Education as a Childhood Government Apparatus in Colombia}

\author{
Yurany Mendoza Giraldo* \\ (iD https://orcid.org/0000-0002-3938-8482 \\ Bernardo Barragán Castrillón** \\ (D) https://orcid.org/0000-0003-1968-8290
}

Tipo de Artículo: Informes de Investigación y ensayos inéditos

Doi: 10.17533/udea.unipluri.20.2.024

Mendoza Giraldo, Y., y Barrangan Castrillon, B. (2020). La educación inicial como dispositivo de gobierno de la infancia en Colombia. Uni-Pluriversidad, 20(2). e20202024. doi: 10.17533/udea.unipluri.20.2.024

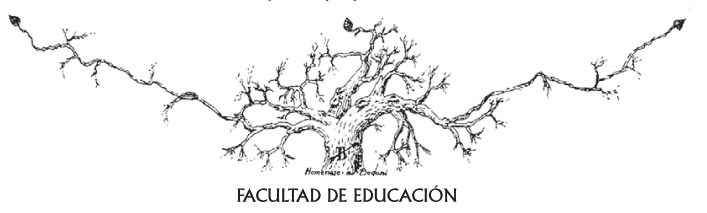

Recibido: 2020-02-23 • Aprobado: 2020-12-22

* Docente secretaria de educación de Rionegro, Colombia.

Email: yurany.mendoza@udea.edu.co

** Universidad de Antioquia, Colombia.

Email: bernardo.barragan@udea.edu.co 


\title{
Resumen
}

Este artículo plantea la educación inicial como un dispositivo de gobierno de la infancia en Colombia. Se acude a la noción de dispositivo y modos de subjetivación en el orden del saber (objetivación) y del poder (sujeción) para explicar estratégicamente su relación. Este trabajo asume una mirada histórica, en tanto interesa describir condiciones de emergencia y posibilidad de un dispositivo que naturaliza unas formas de educar las nuevas generaciones, a través de unas prácticas institucionalizadas que politizan la vida de los niños entre los cero y los seis años. Finalmente, se visibilizan las tensiones entre unas prácticas que han estado en el seno de las familias y unas prácticas educativas que se llevan a cabo en entornos institucionales.

Palabras clave: educación Inicial, Primera Infancia, Subjetividades infantiles, dispositivo, prácticas institucionalizadas.

\begin{abstract}
This article presents early childhood education as a government apparatus for childhood in Colombia. The meaning of apparatus and ways of subjectivation in the order of knowledge (objectification) and power (subjection) are used to strategically explain this relationship. This study considers a historical perspective while it describes emergency conditions and the possibility of a device that naturalizes ways of raising new generations, through institutionalized practices that politicize the lives of children between zero and six years of age. Finally, tensions between family practices and educational practices carried out in institutional environments are made visible.
\end{abstract}

Keywords: Early Childhood Education, Early Childhood, Childhood Subjectivities, Apparatus, Institutionalized Practices. 


\section{Presentación}

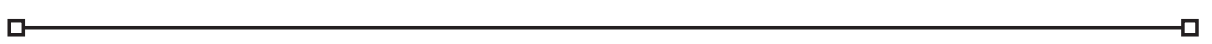

Llegamos a aquel lugar rodeado de niños, una profesora amablemente me atendió y me explicó, brevemente, el programa y los horarios. En el transcurso de la semana podía llevar los documentos y desde ese día podía dejar a mi hijo de 20 meses. Yo dudé un instante, pero tenía que ir a trabajar, así que me decidí a dejarlo. Mi hijo se acercó a unos niños que se entretenían con unos juguetes. En ese instante, la profesora me dijo que podía salir. Yo me fui con la sensación de abandonarlo. Al siguiente día, cuando lo llevé a aquel lugar, mi hijo se aferró a mí y empezó a llorar...

(agosto de 2013)

Este artículo tiene como propósito plantear la configuración de la educación inicial como un dispositivo de gobierno de la infancia en Colombia que produce unos modos de subjetivación en dos órdenes: la objetivación (en el orden de los saberes) y la subjetivación como sujeción (en el orden del poder). Para el desarrollo de estos dos elementos se acude a la noción de dispositivo como "cualquier cosa que de algún modo tenga la capacidad de capturar, orientar, determinar, interceptar, modelar, controlar y asegurar los gestos, las conductas, las opiniones y los discursos de los seres vivientes" (Agamben, 2014, p.18).

Hay hitos importantes que se presentan como condiciones de emergencia de la educación inicial. Por una parte, la declaración de Jomtien en 1990 fijó en una de sus metas "la expansión de la asistencia y de las actividades de desarrollo de la primera infancia, incluidas las intervenciones de la familia y de la comunidad, especialmente para los niños pobres, desasistidos e impedidos" (UNESCO, 1990, p. 10). Por otra parte, estos horizontes guardan una estrecha relación con la estrategia que se venía implementando en Colombia desde 1986 a través de los Hogares Comunitarios de Bienestar (HOBIS) y que precisamente se dirigía a los me- nores de 7 años en condiciones de pobreza con el fin de propiciar su desarrollo psicosocial, moral y físico (Instituto Colombiano de Bienestar Familiar [ICBF], 2012).

Estas dos imágenes, la de Jomtien y la de la creación de los HOBIS permite pensar la configuración de un dispositivo para la Atención y Educación de la Primera Infancia (AEPI). La pregunta es por qué fue necesario este dispositivo y qué modos de subjetivación produce.

En este artículo se plantea, a modo de hipótesis, las condiciones que hicieron posible la educación inicial como dispositivo en una relación de fuerzas entre saberes, prácticas e instituciones, que permitieron una expansión del campo de la educación en los primeros años. Por ejemplo, se delimitó la infancia y se propuso la primera infancia como aquella "etapa del ciclo vital en la que se establecen las bases para el desarrollo cognitivo, emocional y social del ser humano" (Ley 1098 de 2006, 2006, art 29).

En ese orden de ideas, la educación inicial se definió como derecho impostergable, estructurante de la atención integral a la primera infancia, con una apuesta intencionada por el desarrollo integral desde que nacen 
hasta los seis años; parte de los propios contextos e intereses de los niños y las niñas y busca favorecer "las interacciones que se generan en ambientes enriquecidos a través de experiencias pedagógicas y prácticas de cuidado" (Presidencia de la República, 2013, p.68).

Estas nuevas conceptualizaciones alrededor de la educación en los primeros años constituyen un punto de partida para pensar el gobierno de la infancia en el marco de una red de dispositivos que hace de los niños ${ }^{1}$, objeto de saberes y sujetos de prácticas institucionalizadas. Es decir, la educación inicial como práctica sociocultural de aparición reciente está atravesada por unos mecanismos de saber-poder (Foucault, 1999) que operan sobre la primera infancia como población.

\section{LA EDUCACIÓN INICIAL COMO DISPOSITIVO DE GOBIERNO DE LA INFANCIA}

La educación inicial como dispositivo parte del reconocimiento de la implicación de la nuda vida en la vida politizada, ya que para los griegos había una diferencia entre la vida de cualquier individuo por el hecho de ser viviente (zoe) y la forma de vivir propia de un individuo o grupo (bios). Sin embargo, "en los umbrales de la vida moderna la vida natural empieza a ser incluida en los mecanismos y cálculos del poder estatal y la política se transforma en biopolítica" (Foucault, 1976, citado en Agamben, 1999, p.11).

Esta conceptualización de la forma en que operan los mecanismos de poder en la modernidad permite plantear cómo la educación inicial funge como un dispositivo que relaciona saberes, prácticas, instituciones y sujetos en función de un mismo propósito: separar a los niños de su nuda vida $\mathrm{y}$, mediante una exclusión, incluirlos en la vida politizada. En consecuencia, se produce un sujeto sujetado a las políticas del capitalismo mediante una serie de prácticas que regulan, ordenan y controlan su vida como acto de conducción. (Pinto, 2018; Rubio, R, Boero, V y Calquin, 2017).

Ahora bien, se tienen pistas que constituyen elementos que posibilitan el auge de las políticas en relación con la primera infancia. En primer lugar, después de la segunda guerra mundial quedó en evidencia la condición de vulnerabilidad de los niños y la necesidad de protección, atención y educación. Este asunto ha generado movilizaciones sociales a escala global en favor de la infancia y específicamente, de la primera infancia. En segundo lugar, en el año 1989, producto de más de 10 años de negociaciones entre diferentes organismos gubernamentales y no gubernamentales, se proclamó la convención internacional de los derechos del niño (UNICEF, 2006). En tercer lugar, el auge de las Tecnologías de la información y la Comunicación (TIC) y los avances en las ciencias producen y ponen en circulación nuevas imágenes sobre la infancia que modifican las formas de relacionamiento entre las nuevas generaciones y las generaciones adultas. Y, en cuarto lugar, vivimos en una economía de mercado que crea cada vez más necesidades y productos; por ejemplo, el ingreso de la mujer al mercado laboral creó nuevas necesidades en relación con la crianza, la educación y el cuidado de los niños. Por eso, los niños desde los primeros meses asisten a otras instituciones diferentes a la familia y son atendidos y educados por expertos. 
Estos cuatro elementos han contribuido a que los niños estén controlados y vigilados desde que nacen y que se haya expandido el campo de la Atención y Educación de la primera infancia hasta tal punto que, en el presente, funge como un instrumento para erradicar la pobreza en el mundo (UNESCO y WCECCE, 2010), extendiéndose sobre todo en los países en los que se presentan mayores índices de inequidad y desigualdad.

Estos elementos, en tanto agenciamientos, es decir, "un conjunto de singularidades y de rasgos extraídos de un flujo - seleccionados, organizados, estratificados- a fin de converger (consistencia) artificialmente y naturalmente" (Deleuze y Guattari, 2008, p. 408), constituyen las condiciones de posibilidad de la educación inicial y, en ese sentido, configuran las formas políticas, tecnológicas e ideológicas (Naredo, 2013), es decir, son el anclaje de la educación inicial como dispositivo en nuestras sociedades.

Pensar la educación inicial como dispositivo significa, en primer lugar, precisar que hay una intención positiva, es decir, no se pone en duda la afirmación alrededor de la protección, educación y atención integral que requieren los niños, sino sus efectos en tanto dispositivo. En segundo lugar, hay unos medios científicos y tecnológicos que se encargan de posicionar unos discursos alrededor de la importancia de la educación para su desarrollo armónico e integral.

Finalmente, se capitaliza esa noble intención a través de la oferta de programas educativos de calidad que son adquiridos, principalmente, por los estados neoliberales so pretexto de mejorar la calidad de vida de sus poblaciones.

Sin embargo, lo más importante en la configuración del dispositivo son los suje- tos que produce. El resultado de la relación entre la educación inicial y el niño es la primera infancia. En términos de Agamben, "el sujeto es lo que resulta de las relaciones $\mathrm{y}$, por así decir, del cuerpo a cuerpo entre los vivientes y los dispositivos" (Agamben, 2014, p.18).

Por lo tanto, conviene advertir que el dispositivo puede producir unas subjetividades $^{2}$ dóciles, pero autónomas para gestionar su propia sujeción. Es decir, se presenta una instrumentalización del sujeto porque se produce para otro, se pone estratégicamente al servicio del dispositivo. Por ello, es importante abrir discusiones en torno a esas tensiones entre lo objetivo y lo subjetivo, lo institucional y lo experiencial, el sentido común y el saber experto. Estas tensiones están en un campo de relaciones, de disputas y su análisis nos acerca a la comprensión de cómo ha devenido la educación infantil y qué modos de subjetivación produce en tanto educación inicial.

Consideramos además que nombrar los niños como primera infancia los vuelve objeto de intenciones disciplinares y sujetos de prácticas de conducción (Quiceno, 2020). Para ser más precisos, en la expresión primera infancia el devenir del sujeto es problemático porque no se puede dejar al azar su educación, es necesario intencionarla, para producir unas subjetividades funcionales al sistema social, político y económico y, aunque esto ocurre en cualquier momento de la educación, en el caso de los niños de cero a seis años, se disciplina el cuerpo a través del cuidado y no a través de la enseñanza de unos saberes.

Para mostrar el funcionamiento de la educación inicial como dispositivo conviene acudir a la relación entre los modos de subjetivación y objetivación que producen 
los juegos de verdad. Foucault (1994) se pregunta por el cómo se llega a ser un sujeto legitimo de un tipo de conocimiento (subjetivación) y a su vez convertirse en un objeto para su conocimiento (objetivación). En ese sentido, los niños están inscritos en las relaciones de saber y de poder que los adultos definimos. Los niños participan de los juegos de verdad que la misma sociedad ha establecido. Por ejemplo, que el cerebro se desarrolla más en los primeros años de vida, que la inversión en la primera infancia generan altas tasas de retorno para un país (Presidencia de la República, 2013).

Como dispositivo, la educación inicial se expande, se especializa y constituye un ejercicio biopolítico. Foucault (2007) traza un mapa sobre las relaciones de poder que en la modernidad constituyen el sujeto y lo vuelven objeto de políticas y lo expresa de la siguiente manera, "durante milenios el hombre siguió siendo lo que era para Aristóteles: un animal viviente y además capaz de una existencia política; el hombre moderno es un animal en cuya política está puesta en entredicho su vida de ser viviente" (p.173).

Esto se evidencia en las formas estratégicas que han emergido en Colombia para la educación de los niños de cero a seis años. Es decir, estos niños tienen una experiencia de la infancia que resulta problemática. Por lo tanto, se le priva de esa experiencia (una inclusión mediante una exclusión) para que sea otro. Es menester, entonces, excluirlo de esa nuda vida, de esa vida de ser viviente mediante la educación inicial. En ese sentido, la pregunta es por qué la política occidental se convierte en medio de una exclusión que a la vez es una implicación (Agamben, 1999).

Así, por ejemplo, la política integral para la primera infancia se funda en una inclusión excluyente, es decir, se incluye a los niños en la vida institucional como forma política y se excluyen de la vida familiar; bien sea porque se desconfía de la capacidad de la familia para educar y atenderlos de manera integral o porque se le asignan roles productivos, es decir, las familias hoy están en el mercado laboral, en tanto, sus hijos son atendidos, cuidados y educados a través de nuevas prácticas institucionalizadas.

En suma, la educación inicial como dispositivo de gobierno despliega en su función de agenciamiento, una pluralidad de elementos que endurecen la comprensión de la subjetividad de los niños. Por esta vía, crea un proyecto formativo como producción de subjetividades que recoge elementos jurídicos, tecnológicos, médicos, pedagógicos, psicológicos y económicos y, al mismo tiempo, sujeta la experiencia de la infancia mediante la ampliación objetiva de su campo de acción a las prácticas institucionalizadas. A continuación, se detalla cómo ocurre ese gobierno de la infancia en dos formas estratégicas: las formas objetivas y las formas institucionales.

\section{LOS SABERES: LA OBJETIVACIÓN DE LA INFANCIA}

"Entendemos por saber el conjunto de conocimientos de niveles desiguales (cotidianos o con pretensión de teóricos) cuyos objetos son enunciados en diversas prácticas y por sujetos diferentes y que siempre está soportado en un sujeto o experto y arraigado estratégicamente en una institución" (Zuluaga, 1999, p.148).

El punto de partida de este planteamiento tiene que ver con los saberes que se han insertado alrededor de la educación inicial 
en las últimas dos décadas y que la convierten en objeto de estudio. Esto es, unos saberes que circulan por el soporte de unos expertos, enunciados en unas prácticas e institucionalizados bajo diferentes disciplinas con estatuto teórico y bajo unos regímenes de verdad que movilizan la infancia para conocerla, ordenarla y controlarla.

Vale la pena decir, por ejemplo, que la lupa que se le ha puesto a la infancia, especialmente en el siglo XXI, ha transformado las maneras de pensarla y de relacionarnos con ella porque ha propiciado la circulación de argumentos de tipo científico, político-jurídico y social, psicológico e, incluso, pedagógico que justifican la inversión de recursos económicos en la primera infancia para el progreso de una nación (Ministerio de Protección social et al., 2007).

Los saberes en este nuevo escenario "Colombia por la primera infancia" se instrumentalizan en la medida en que las investigaciones giran en torno a justificar unas acciones predeterminadas en las formas jurídicas como formas de verdad. Vale aclarar que lo que se cuestiona no es la importancia de generar unas condiciones dignas para los niños que viven en condición de pobreza ${ }^{3}$, sino los efectos de las estrategias que se crean para darles solución a esas problemáticas heredadas y creadas sobre la infancia.

Ahora bien, estas estrategias están contempladas en la Guía operativa para la prestación del servicio de Atención Integral a la Primera Infancia. Allí se explican los referentes conceptuales y las modalidades de atención integral: modalidad entorno familiar, modalidad entorno comunitario y modalidad entorno institucional. En los referentes conceptuales abordan el niño, la niña y el desarrollo infantil, las competencias en la primera infancia, el papel de los agentes educativos y las estrategias educativas para promover el desarrollo de competencias. (Ministerio de Educación Nacional [MEN], 2009).

En este sentido, los saberes pedagógicos y psicológicos acerca del desarrollo del niño y la niña ponen el énfasis en su integración mediante formas estratégicas que producen unas subjetividades competentes y funcionales a las sociedades de mercado y los Estados neoliberales. Se trata entonces de una objetivación estratégica, es decir, una forma de organización en una institución, con unas prácticas que vuelven al sujeto objeto de unos saberes expertos y lo entienden como el producto de unas relaciones de fuerza y de control encaminadas a convertir este sujeto en algo funcional para una sociedad o para un propósito determinado.

En el marco de la guía operativa aparece la modalidad de atención en entorno institucional que va dirigida a niños menores de cinco años, ubicados en zonas urbanas y que incluye nutrición, cuidado y educación inicial 5 días a la semana, en jornadas de ocho horas diarias (MEN, 2009). Al preguntarse por las razones objetivas (en el ámbito de los saberes) que justifican apartar a los niños tanto tiempo de sus progenitores y ubicarlos desde tan temprana edad en una jornada cercana a lo laboral (40 horas semanales) y en un espacio (por lo general cerrado), se aprecia que se pasa del orden de lo viviente al orden del sujeto que se produce, es decir, se ordena la vida del niño desde muy temprano para asegurar unas subjetividades que se estructuran a partir de la relación estratégica entre los saberes y las prácticas institucionalizadas.

Pareciera, en el escenario actual, que las intencionalidades políticas y económicas se articulan con los saberes sobre la Educación 
Inicial y configuran una estrategia positiva, de producción, de regulación y de control que termina definiendo la vida de los niños en todos sus aspectos. En el presente no es posible pensar en la infancia sin esa relación necesaria con los saberes expertos, poniendo en entredicho la experiencia que tienen las familias para educar a sus hijos y produciendo así unos efectos sobre sus subjetividades.

Ahora, los saberes sobre la infancia, además de ser instrumentalizados por intencionalidades políticas y económicas, han escindido al sujeto para controlarlo en tanto objeto de conocimiento. Por ejemplo, la psicología infantil se encarga del desarrollo emocional y psíquico del niño; la pedagogía infantil, de su educación; la fonoaudiología, de su lenguaje; la neurología infantil, del desarrollo y el funcionamiento del cerebro de los niños desde edades muy tempranas.

Por lo tanto, esos saberes modulan unas prácticas con la infancia que tienen que ver con el control y la vigilancia del desarrollo y recientemente del aprendizaje de los niños. Es decir, la psicología y la pedagogía hacen seguimiento a las habilidades de los niños y a las estrategias que se requieren para potenciarlas. Así mismo, las escalas psicométricas son decisivas a la hora de definir el desarrollo normal de los niños y los beneficios de la educación inicial (Cortés y Garcia, 2017; Gutiérrez, S y Ruiz, 2018). Lo anterior constituye el cerco epistemológico para la puesta en marcha de programas para la primera infancia.

Igual, la pedagogía infantil ${ }^{4}$ históricamente se ha ido nutriendo de distintos discursos que vienen del área de la salud y de las ciencias sociales, y van consolidando un campo de prácticas intencionadas (exper- tas), atribuibles por algunos a los técnicos $\mathrm{u}$ operarios, pero que fundamentalmente funcionan sobre la infancia conduciéndola en un campo de relaciones.

El análisis de los saberes que fundamentan la educación de los niños entre los cero a los seis años y justifican las prácticas institucionalizadas permite pensar en la objetivación (Foucault,1996) de la infancia como acto de gobierno. Por lo tanto, la pregunta que deviene es cómo el Estado ordena los tiempos, espacios, actividades y disciplina los cuerpos de los niños a través de prácticas de cuidado, nutrición y educación inicial.

Al respecto, Agamben (1999) anota la contradicción que representa la conquista de espacios, libertades y derechos en simultánea con una inscripción de la vida al orden de lo estatal, dando lugar a ese poder soberano del que se quería escapar. Es decir, el Estado, so pretexto de la garantía de unos derechos desplaza y hace que la familia asuma un rol diferente en la educación de sus hijos.

En conclusión, la infancia hoy se objetiva a través de los saberes que escinden al sujeto en fragmentos de saberes y a la vez lo articulan para crear un sujeto competente, producto de esas relaciones. Así mismo, se configuran unas prácticas pedagógicas subordinadas al capitalismo contemporáneo y a un Estado neoliberal. Jean Louis Faldrin (citado por Carli, 1999) anotaba que:

La infancia se convirtió en un objeto emblemático del siglo XX fijado por los saberes de distintas disciplinas, capturado por dispositivos institucionales, proyectado hacia el futuro por las políticas de Estado y transformado en metáforas de utopías sociales y pedagógicas (p.1.) 


\section{LAS PRÁCTICAS INSTITUCIONALIZADAS}

Al decir de Foucault, citado por Castro (2004), las prácticas se entienden como:

La racionalidad o regularidad que organiza lo que los hombres hacen sistema de acción en la medida en que están habitados por el pensamiento, (objeto de reflexión y análisis) — que tienen un carácter sistemático (saber, poder, ética) y general (recurrente), y que por eso constituye "una experiencia" o un pensamiento. (p.427)

En este sentido, las prácticas constituyen un campo de relaciones entre unos saberes, un sujeto que las soporta y unas instituciones que tienen como función la producción de una subjetividad. Ahora bien, cuando se institucionalizan, éstas se ordenan, se regulan, se orientan y se conducen como formas elaboradas que las delimitan y las mantienen en un cerco epistemológico producido por los saberes, en un cerco normativo producido por las políticas y en un cerco fáctico (de producción) generado por las mismas prácticas.

Las prácticas institucionalizadas en tanto ese grupo de formas y rutinas de organización que tienen como función la generación de reglas y medidas legítimas y además tienen una afirmación legal (Dubet, 2013), se convierten en soporte de la política de atención integral a la primera infancia porque permiten regular cada uno de los elementos que intervienen en el desarrollo de los niños, cuyos componentes pasan por la garantía de sus derechos tales como: educación inicial, atención y cuidado $\mathrm{y}$, nutrición y salud.

Si bien, la función legal (políticas para la primera infancia) es mejorar la calidad de vida de las madres gestantes y los niños menores de cinco años clasificados en los distintos niveles del Sistema de Identificación de Potenciales Beneficiarios de Programas Sociales (Sisbén), es en el marco de la creación de nuevas instituciones, saberes, expertos y prácticas que las subjetividades infantiles se performan como funcionales al dispositivo de la educación inicial. Es decir, existen mecanismos de conducción al interior de estas instituciones que regulan de manera objetiva el tiempo, el espacio, el cuerpo y la vida misma, modelando una subjetividad objetiva.

Ahora, es importante insistir sobre el cuidado de la niñez desde que nace hasta que adquiere la capacidad de valerse por sí misma. Lo problemático está en que la atención integral y la formación de unas subjetividades infantiles configuran la institucionalidad politizada de la primera infancia. Podría señalarse que se pasa de un orden de lo privado a lo público en la esfera de lo social, lo cual hace las cosas más difíciles para los niños, pues estos necesitan un espacio intimo para su maduración (Arendt, 2016, p. 289).

Algunos referentes muestran que en las dos primeras décadas del siglo XXI se consolidó el marco normativo para la atención integral de la primera infancia en Colombia a través de varias acciones. Por ejemplo, se dieron cambios en la legislación para aumentar la inversión en este sector de la población (Conpes 109 de 2007 y la ley 1295 de 2009), se crearon instancias multisectoriales para la atención integral de la primera infancia (Decreto 4875 de 2011) y, por último, se diseñó una estrategia para la atención integral a la primera infancia hasta elevarla 
a política pública de Estado mediante la Ley 1804 de 2016.

Por lo tanto, el documento de la Política nacional titulado Colombia por la primera infancia (Documento conpes 109. Política Pública Nacional de Primera Infancia, 2007) abre todo un marco normativo en relación con la atención integral en la cual, el componente educativo juega un papel importante. Incluso, podría leerse que, con la incorporación de la mujer al mundo laboral y el cambio en la configuración de la familia, se vuelve necesario tejer redes de apoyo con otros agentes socializadores (padre, madre, tíos, profesionales) para la creación de ambientes protectores que les garanticen los derechos fundamentales: salud, nutrición, buen trato, educación inicial a este sector de la población, es decir, se institucionaliza una manera de conducir, regular y controlar esta población.

Igualmente, en materia educativa, vale la pena destacar que, en el año 2017, se publicaron las bases curriculares para la educación inicial y preescolar, las cuales introdujeron modificaciones importantes en la manera de concebir las prácticas pedagógicas en todos sus componentes: planificación, ejecución y evaluación. La intencionalidad de este documento fue la promoción del desarrollo y el aprendizaje en los niños y las niñas (MEN, 2017). Esto es, se consolida una estrategia discursiva que funciona por la vía de la relación que tiene la política educativa con los expertos y con la institucionalidad.

En resumen, se pretende hacer visible que las prácticas alrededor de los niños tienen un componente institucional que produce una serie de dispositivos del orden arquitectónico, temporal, de la experiencia y del encierro para el cuidado, cuyo efecto es la producción de unas subjetividades.
Ahora bien, en el marco de esa relación es importante anotar que en Colombia se ha establecido una continuidad de dos prácticas institucionalizadas que operan de manera distinta sobre la infancia. Por un lado, para la educación inicial se crea una institución que opera la modalidad atención integral en entorno institucional, llamada unidades de servicio o Centro de Desarrollo Infantil (CDI); por el otro, el establecimiento educativo (escuela) ofrece el grado transición del nivel preescolar en la modalidad escolar, tal como lo establece el artículo 17 de la Ley General de Educación (Ley 115, 1994, art 17).

Es decir, los niños ya no pasan de la familia a la escuela, ahora el tránsito se hace más largo, van de la familia a los CDI, y de los CDI a la escuela. Esta continuidad produce una ruptura en tanto la educación inicial se basa en el discurso de la infancia como sujeto de derechos y como sujeto político. Mientras que en la educación preescolar subyace un discurso moderno, de preparación para una etapa escolar (Sandoval, 2006).

Lo anterior se sustenta en que una está centrada en la producción de una subjetividad infantil basada en el cuidado; en tanto la otra está soportada de forma estratégica en los procesos educativos y pedagógicos que se fundan en los saberes escolares (Barragán, 2018; Herrera, 2016). Esta diferencia es importante porque delimita un campo de tensiones entre lo que significa el cuidado y la atención en una sociedad como la nuestra y lo que implica un proceso de escolarización moderno.

Se considera que los desarrollos en las políticas educativas para la primera infancia hacen parte de esas condiciones de emer- 
gencia de la educación inicial como dispositivo que crea un sujeto necesitado de experiencias enriquecedoras para desarrollar su potencial. Lo que en otro tiempo eran prácticas cotidianas que sucedían al interior de la familia (el afecto, el cuidado, la asistencia), ahora se tornan prácticas expertas que se extienden principalmente a la población más vulnerable.

En este orden de ideas, también se observa una naturalización de la educación inicial en la sociedad pues, al parecer, se instaló una nueva verdad sobre su importancia. De ahí que funcione como ingeniería social, como prevención de futuros desvíos (Runge, Carrrillo y Muñoz, 2012), centrándose en la educación de los niños de los cero a los seis años. Por ello, los roles de cuidado, atención y educación que tenía la familia se han ido transfiriendo paulatinamente al Estado, a través de las instituciones para la primera infancia que se han ido masificando en la última década.

Otra de las condiciones de emergencia de la educación inicial está relacionada con la necesidad que hoy asiste a las familias de conseguir un empleo para ofrecerle a los hijos condiciones de vida digna. Lo anterior tiene conexión con el capitalismo contemporáneo que modula el relacionamiento entre la familia y los niños asociado con fenómenos como la participación de la mujer en el mercado laboral; ello ha implicado transformar su rol y asumir una maternidad distinta. Lo paradójico es que mientras el Estado financia programas para la primera infancia que operan instituciones privadas, los miembros de la familia dejan de cuidar a sus hijos para acceder al mercado laboral.

En últimas, las condiciones de emergencia de las prácticas institucionalizadas están en dos vías. Una tiene que ver con el capitalismo contemporáneo (Katz, 2003) que modula las relaciones de producción en todos los órdenes: económico, laboral, cultural y social. La otra tiene que ver con la circulación de discursos que validan el nuevo acervo tecnicista y experto, por lo tanto, se consolida una nueva cultura infantil basada en el control y la regulación de los tiempos, espacios, rutinas de sueño y alimentación de los niños.

\section{A MOdO DE CIERRE: LA INSTITUCIONALIZACIÓN DE LA PRIMERA INFANCIA}

口

La educación inicial como dispositivo de gobierno de la infancia produce unos efectos que pueden sintetizarse en la relación que se produce entre los saberes y las prácticas institucionalizadas. Fundamentalmente, estas dos formas estratégicas producen un efecto de desplazamiento en la educación infantil que ahora tiene una nueva institucionalidad: los CDI. A diferencia de la escuela maternal o jardín de infancia que se configuró a principios del Siglo XX, se trata de una institu- ción objetivada por saberes provenientes de múltiples campos disciplinares en la misma dirección del niño como un Frankenstein (Meirieu, 2007).

Hoy tenemos una política educativa que prescribe e interviene un segmento de la población (primera infancia) con una oferta de distintos servicios: cuidado, salud, nutrición y educación inicial. Lo problemático es que las prácticas educativas empiezan a adquirir nuevas formas, las formas institucionales 
que globalizan las maneras de criar y enseñar a las nuevas generaciones.

El perfeccionamiento de unas prácticas institucionalizas puede estar relacionado con lo que han descrito dos autores latinoamericanos sobre la infancia y su educación. Por una parte, los cambios culturales que modifican las relaciones entre hijos y padres hace que aparezcan cada vez más bebés en las escuelas (Narodowski y Snaider, 2017). Y por otra, asistimos a la emergencia de la infancia como primera infancia que implica una des-conceptualización de la misma (Quiceno, 2020).

Finalmente, se insiste en que las prácticas institucionalizadas producen unas subjetividades útiles al mercado que se moldean mediante el encierro, el estableci- miento de horarios, rutinas, reglamentos, la imposición de juegos y juguetes, y ya no solamente desde los saberes que dicen qué se debe hacer con la infancia. De tal manera, las prácticas se vuelven actos de gobierno que conducen a los niños, se apropian de sus cuerpos, de sus mentes y de sus emociones.

De manera concreta, se ha instalado en nuestra sociedad una verdad y consiste en que los niños de cero a seis años necesitan atenderse mediante unas prácticas expertas institucionales para monitorear la vida y regular y controlar su desarrollo y aprendizaje como una práctica de gobierno. Esa condición performativa que tiene la educación infantil hoy opera como una estrategia biopolítica, es decir, como gestión y control de la vida en el sentido que nada queda por fuera de ella.

\section{REFERENCIAS}

1. Para este artículo se usará niños en plural para incluir los géneros y abordar principalmente el sujeto y se usará infancia y primera infancia para hablar de la construcción conceptual e histórica de ese sujeto.

2. Cuando se emplea la palabra subjetividades en el orden de la infancia, deviene la pregunta por el sujeto que se nombra, por las imágenes que evoca cuando se dice infancia, infancias, infancia temprana, niñez, párvulos, recién llegados o primera infancia y por el paradigma que subyace en estas formas de nombrar los niños, pues denotan formas de conceptualizarlos en un momento histórico. Por ejemplo, la expresión primera infancia es del orden jurídico y cobra fuerza en Colombia a partir de la promulgación del Código de la Infancia y la Adolescencia (Ley 1098 de 2006). De hecho, dicha expresión y la actuación positiva sobre ella, permite a los Estados neoliberales intervenir la población y vincular allí un nuevo producto o servicio que tiene nombre de derecho: educación inicial, con un propósito, potenciar el desarrollo económico de una nación. En ese sentido, han circulado en el país las investigaciones de Heckman y Masterov que demuestran que una intervención enriquecida de los entornos familiares en los primeros años de vida contribuye con la productividad de la fuerza laboral de un país (citado en Portafolio, 2005).

3. Según cifras del DANE de julio de 2019, en Colombia hay 9,69 millones de colombianos en pobreza multidimensional de los cuales, 1.1 millones de personas se suman entre 2016 y 2018. Los departamentos con la más alta cifra son Guainía $(65,0 \%)$, Vaupés $(59,4 \%)$, Vichada $(55,0 \%)$, La Guajira $(51,4 \%)$ y Chocó $(45,1 \%)$. De acuerdo con Juan Daniel Oviedo, la pobreza multidimensional se mide teniendo en cuenta 
variables como acceso a servicios de salud, educación, vivienda, mercado laboral, tecnologías de la información y la comunicación (Becerra, 2019).

4. La pedagogía se ha ido modificando hasta dar lugar a la pedagogía infantil. De acuerdo con Sandoval (2006), podría parecer redundante hablar de pedagogía infantil puesto que en un principio la pedagogía estuvo relacionada con enseñar a los niños, sin embargo, para este autor hay dos razones que justifican la especificidad de la denominación, una tiene que ver con extensión de la palabra pedagogía para cualquier grupo etario, y la otra, con la resemantización de la palabra compuesta a partir de la evolución del conocimiento relacionado con la infancia y su desarrollo, así como las nuevas demandas socioculturales relacionadas con cada nueva generación de seres humanos (Sandoval, 2006, p.10).

\section{REFERENCIAS}

Agamben, G. (1999). Homo Sacer. El poder soberano y la nuda vida. Pretextos.

Agamben, G. (2014). Qué es un dispositivo. El amigo. La Iglesia y el Reino. Anagrama.

Arendt, H. (2016). Entre el pasado y el futuro. Ocho ejercicios sobre reflexión política (Primera ed). Ariel.

Barragán, B. (2018). Políticas educativas y escolarización. En Barragán (editor). Reformas Educativas:escolarización y gubernamentalidad en Colombia. 18-34 Editoria Universidad de Antioquia y Grupo Historia de la Práctica Pedagógica.

Becerra, L. (15 de julio de 2019). Así es el mapa de la pobreza en Colombia que debe sortear el presidente Iván Duque. La República. https://www.larepublica.co/economia/asi-es-el-mapa-dela-pobreza-en-colombia-que-debe-sortear-ivan-duque-2884637

Carli, S. (1999). La infancia como construcción social. De la familia a la escuela. Infancia, socialización y subjetividad, 1-6. https://des-for.infd.edu.ar/sitio/upload/Carli-La-infancia-como-construccion-social.pdf

Castro, E. (2004). El vocabulario de Michel Foucault. Prometeo. https://doi.org/Biblioteca digital

Cortés, A., y Garcia, G. (2017). Estrategias pedagógicas que favorecen el aprendizaje de niñas y niños de 0 a 6 años de edad en Villavicencio- Colombia. Revista Interamericana de Investigación, Educación y Pedagogía, RIIEP, 10(1), 125-143. https://doi.org/10.15332/s1657-107x.2017.0001.06

Deleuze, G., y Guattari, F. (2008). Mil mesetas. Capitalismo y esquizofrenia (octava ed). Pretextos.

Dubet, F. (2013). El declive de la institución: profesiones, sujetos e individuos en la modernidad. Gedisa.

Foucault, M. (1994). Dits et ecrits. T.2. Gallimard.

Foucault, M. (1999). Estrategias de poder: Obras esenciales,vol. II.

Foucault, M. (2007). Historia de la sexualidad. 1-La voluntad de saber (Siglo XXI). 
Gutiérrez, S., y Ruiz, M. (2018). Impacto de la Educación Inicial y Preescolar en el neurodesarrollo infantil. IE Revista de Investigación Educativa de la REDIECH, 9(16), 67-82. http://www.scielo. org.mx/scielo.php?script=sci_arttext\&pid=S2448-85502018000200033\&lng=es\&nrm=iso\&tlng=es\%0Ahttp://www.rediech.org/ojs/2017/index.php/ie_rie_rediech/article/view/108

Herrera, C. (2016). La infancia en la Historia de la Pedagogía en Colombia. En Noguera, C; Álvarez, A y Herrera, C (editores). Lecciones de historia de la pedagogía en Colombia. Escuela, maestro e infancia(s). 159-215 Magisterio Editorial.

Instituto Colombiano de Bienestar Familiar -ICBF- (2012). Concepto 08 de 2012. https://www.icbf. gov.co/cargues/avance/docs/concepto_icbf_0000008_2012.htm

Katz, C. (2003). Capitalismo contemporáneo: etapa, fase y crisis. (Prueba) Ensayos de Economía (Prueba), 13(22), 36-68. https://revistas.unal.edu.co/index.php/ede/article/view/24975/25520

Ley 115 de 1994. Por el cual se expide la ley general de educación. 08 de febrero de 1994. Diario oficial [D.O]; 41214 (Colombia). http://www.secretariasenado.gov.co/senado/basedoc/ ley_0115_1994.html

Ley 1098 de 2006. Código de la Infancia y la Adolescencia. 08 de noviembre de 2006. Diario oficial [D.O] 46446. (Colombia). https://www.icbf.gov.co/cargues/avance/docs/ley_1098_2006.htm

Meirieu, P. (2007). Frankestein Educador (Tercera re). Laertes.

Ministerio de Educación Nacional -MEN- (2009). Guia operativa para la prestación del servicio de Atención Integral a la Primera Infancia (p. 164). https://www.mineducacion.gov.co/primerainfancia/1739/articles-178515_archivo_pdf_ruta_version_marzo_2009.pdf

Ministerio de Educación Nacional -MEN- (2017). Bases curriculares para la Educación Inicial y Preescolar. https://www.mineducacion.gov.co/1759/articles-341880_recurso_1.pdf

Ministerio de Protección Social, Ministerio de Educación Nacional, Instituto Colombiano de Bienestar Familiar (2007). Documento conpes social 109. Política Pública Nacional de Primera Infancia. Colombia por la primera infancia. https://siteal.iiep.unesco.org/sites/default/files/sit_accion_files/ co_0440.pdf

Naredo, J. (2013). Ideología político-económica dominante y claves para un nuevo paradigma. $R e$ vista de Economía Crítica, 16. http://tratarde.org/wp-content/uploads/2014/01/Revista_Economia_Critica_16-PENSAR-LA-TRANSICIÓN-I.pdf\#page $=108$

Narodowski, M., y Snaider, C. (2017). ¿Bebés en las escuelas? Infancias hiperescolarizadas en una cultura prefigurativa. Revista Latinoamericana de Ciencias Sociales, Niñez y Juventud, 15(1), 45-57. https://doi.org/10.11600/1692715x.1510121052016

Pinto, M. (2018). La educación inicial en Bogotá-Colombia y su fundamentación en la psicología. La experiencia de un jardin infantil (Tesis de doctorado). Centro de Estudios Avanzados en Niñez y Juventud, CINDE. https://repository.cinde.org.co/handle/20.500.11907/2295.

Portafolio. (2005). Aumentar la productividad invirtiendo en los niños. El tiempo. https://www.portafolio.co/economia/finanzas/aumentar-productividad-invirtiendo-ninos-275666 
Presidencia de la República. (2013). Estrategia de atención integral a la primera infancia: Fundamentos políticos, técnicos y de gestión. http://www.deceroasiempre.gov.co/Prensa/CDocumentacionDocs/Fundamientos-politicos-tecnicos-gestion-de-cero-a-siempre.pd

Quiceno, H. (2020). Aproximación crítica: Desde la infancia a la primera infancia. En M. Aguilar, D y Giraldo (Ed.), Lecturas críticas sobre la infancia: tensiones entre la modernidad y la contemporaneidad. (Aula y Uni, 15-49).

Rubio, R., Boero, V., y Calquin, C. (2017). Biopolítica del cuidado en contextos neoliberales:reflexiones sobre el programa Chile Crece contigo. En J. A. (compiladora) Patiño (Ed.), Cuidados y políticas públicas en América Latina. Asuntos del VI seminario Internacional de Familia. (pp. 111-136). CLACSO. http://biblioteca.clacso.edu.ar/clacso/gt/20171124113150/Cuidados_y_politicas_publicas.pdf

Runge, A., Carrillo, S., y Muñoz, D. (2012). Los “mega” jardines infantiles de Medellín y el gobierno de la población infantil. Itinerario Educativo, 26(60), 55-74.

Sandoval, C. (2006). Educación Inicial y Pedagogía Infantil: evolución y estado actual de un itinerario. Cuadernos Pedagógicos, 25, 9-28. https://revistas.udea.edu.co/index.php/cp/issue/download/3480/Cuadernos Pedagógicos \%2325 - PDF

UNESCO. (1990). Declaración Mundial sobre Educación para Todos y el Marco de Acción para Satisfacer las Necesidades Básicas de Aprendizaje. Jomtien, Tailandia 5 al 9 de marzo de 1990. http://www.unesco.org/education/pdf/JOMTIE_S.PDF

UNESCO, \& WCECCE. (2010). Marco de Acción y cooperación de Moscú: Aprovechar la riqueza de las naciones. http://www.unesco.org/ulis/cgi-bin/ulis.pl?catno=189882\&set=4D5E86D7_2_159\&gp $=1 \&$ lin $=1 \& 11=1$

UNICEF. (2006). Convención sobre los derechos del niño. 20 de noviembre de 1989. https://doi. org/10.18356/51f8034c-es

Zuluaga, O. L. (1999). Pedagogia e Historia: La historicidad, la enseñanza un objeto de saber. Universidad de Antioquia-Antropos-Siglo del hombre editores. 